\title{
El pensar de la acción
}

\author{
CARMEN CORRAL
}

Las siguientes reflexiones sobre la obra de Hannah Arendt parten de un interés centrado en nuestro presente. Se trata de interrogantes que apuntan a una comprensión de las representaciones de nuestra experiencia actual, a un pensar las posibilidades de la acción. La cuestión clave es: ¿cómo vernos capacitados para empezar a comprender nuestra ubicación, como sujetos individuales y colectivos que somos, $y$ volver a reconquistar nuestra capacidad de actuar y luchar, neutralizada en estos momentos por un sinfín de confusiones?

Espero que la respuesta a tal pregunta quede sugerida a lo largo del texto, para lo que deseo apuntar en primer lugar que sólo desde una concepción de lo real como territorio abierto a las diferentes posibilidades podemos aproximarnos a cuestiones como la planteada: «la realidad en la que estamos no está hecha, no encontra-

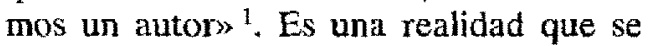
va haciendo a cada momento, un espacio nuevo para cada acción, un lugar abierto a lo plural desde su intrínseca pluralidad.

Esa concepción abierta de to real se encuentra una y otra vez en los textos de Hannah Arendt, y es de clla de quien retomo la siguiente propuesta: «lo que propongo es muy sencillo: nada más que pensar en lo que hacemos ${ }^{2}$, poniendo un énfasis especial en cl hacentos. Así, mi exposición sólo pretende abordar una temática que podría expresarse como «pensar la acción» o el upensar de la acción», para lo que no deseo alejarme mucho de las palabras empleadas por una pensadora olvidada durante bastante tiempo en nuestro pais, aunque ahora vuelve a estar de "rabiosa actualidad", si bien muchas veces se interpreta más que se escucha.
El pensamiento de Arendt tiene dos momentos claros que ella denomina la vita activa y la vita contemplativa. El análisis de la primera lo lleva a cabo en su obra La Condición Humana, texto en el que se centra en las nociones de trabajo, labor y acción ${ }^{3}$. Nociones como las de acción, identidad e historia son vistas en una mutua y estrecha relación, y se engloban en lo que la autora define como la acondición humana", cuyos elementos constitutivos son la natalidad y la pluralidad.

Cuando Arendt plantea el concepto «natalidad» lo hace caracterizándolo como la categoría central del pensamiento político frente a la «mortalidad", categoría que había sido el eje central del pensamiento metafísico. Arendt entiende la natalidad como la creación, el surgimiento de novedades, como aquello que es propio de la esfera humana. Esta creación es vista como «proceso», como un proceso entre seres humanos que posibilita la acción humana, la única actividad pública en la que no median objetos sino sujetos. El agente actúa como «miembro de la especie», posibilitando de este modo la aparición de la fertilidad. Es la categoría de "natalidad» la que permite entender lo nuevo como el crear. $« E l$ hecho de que el hombre sea capaz de acción significa que cabe esperar de él lo incsperado, que es capaz de realizar to infinitamente improbable» ${ }^{4}$. La natalidad es la matriz de las acciones, es el acto de romper con el pasado, la irrupción de algo kinédito» en el continuum temporal. Por todo ello, Arendt considera que la acción es la realización de la condición humana del nacer, del comenzar y de la pluralidad entendida como «distinción», como aquello que permite la constitución de la propia individualidad ${ }^{5}$. 
El concepto de acción que maneja Arendt es cercano a los de Agustín o Kant, autores que resultan bien conocidos. $\mathrm{La}$ acción hace aparecer lo novedoso, injcia una cadena de acontecimientos con motivos y propósitos previamente diseñados $\mathrm{y}$ autónomamente decididos. Arendt define el actuar como «tomar una iniciativa, comenzar como indica la palabra griega arkhein, o poner algo en movimiento, que es el significado original del agere latinos ${ }^{6}$. Pero todos estos sentidos se resumen en una breve frase: «actuar es errar, extraviarse» ${ }^{7}$. Se trata de un extraviarse que se articula en dos momentos: un comienzo, una epuesta en marcha» por parte de una única persona, $y$ un final, el momento en que son muchos los que «acaban» lo cmprendido, el cncuentro con la pluralidad.

Se trata de los momentos de la natalidad y de la pluralidad a los que antes me refería, de tal modo que la acción, además de su contenido, también establece relaciones, de to que deriva su resistencia a sentirse clausurada. Sin embargo, al mismo tiempo que se da esta apertura a la pluralidad y al establecimiento de relaciones, se hacen patentes las tres frustraciones que son inherentes a la acción: el anonimato, la impredecibilidad y la irrevocabilidad.

\section{Las frustraciones de la acción}

Empecemos por el anonimato. Cuando aparece la acción, surge también el discurso, realización de esa otra característica propiamente humana que enunciaba como la pluralidad. No es posible una acción sin discurso: el actor sólo es tal si median las palabras, y de la unión de ambas realizaciones (acción y discurso) surge la identidad. Según Arendt, «la manifestación de "quién es alguien" se halla implícitamente en el hecho de que, en cierto modo, la acción muda no existe, o si existe es irrelevante; sin palabra, la acción pierde el actor, y el agente de los actos sólo es posible en la medida en que es, al mismo tiempo, quien dice las palabras, quien se identifica como el actor y cnuncia lo que está haciendo, lo que ha hecho, o lo que trata de hacer" ${ }^{8}$. Isak Dinesen, por quien Arendt siente gran afecto ${ }^{9} \mathrm{y}$ a la que cita en muchos momentos de su análisis de la condición humana, escribía en una de sus obras: «sólo la historia tiene autoridad en el entero universo para responder a este grito que sale de lo más profundo de sus personajes, este único grito de todos y cada uno de ellos: "¿Quién soy?"》" 10.

Junto a la frustración del anonimato de la acción se encuentran su inherente falta de predicción y la irrevocabilidad del proceso. La impredecibilidad apunta la imposibilidad de conocer las consecuencias de la acción, puesto que son otros los que continúan la acción que uno inicia. Además, de nuevo en palabras de Dinesen, «es probable que quienes puedan llevar a cabo acciones extraordinarias, no siempre sean capaces de concebirlas»" "Esta frustración de la acción se relaciona con el carácter revelador de la acción y del discurso en los que se muestra la identidad. De este surgimiento de identidades nace la esfera política. Es la aparición del yo y de los otros lo que precede a la organización politica. Aunque, como veremos más adclante, puede decirse que ya es organización política.

La tercera frustración, la imevocabilidad, se refiere a la incapacidad para poder deshacer to ya hecho, a lo imposible de «volver a empezar». Arendt dice que frente a estas tres frustraciones de la acción se ha tratado de buscar un sustituto de la misma que pudiese escapar a la irresponsabilidad moral y fortuita provocada por una pluralidad de agentes. Pero, para hablar de responsabilidades, no podemos referimos a los motivos o a los objetivos que nunca se centran en una única persona. Un acto sólo puede ser juzgado por su realización y no por su motivación o por su logro, 
«la acción sólo puede ser juzgada por el criterio de grandeza debido a que en su naturaleza radica el abrirse paso entre lo comúnmente aceptado y alcanzar 10 extraordinario, donde cualquicr cosa que es verdadera en la vida común y cotidiana ya no se aplica, puesto que todo lo que existe es único y sui generis...» 12 .

Estas calamidades de la acción, estas frustraciones, provienen de la condición humana de la pluralidad, condición que es necesaria, sin embargo, para la aparición de la esfera pública. Con todo, hablar de fines y medios presupone un sistema moral. Tal es la razón que ha llevado a tergiversar el actuar y sustituirlo por el hacer, cambio que comporta una degradación de lo político en meros medios para la consecución de fines "más elevados". Esto no es más que convertir la acción en mero instrumento, en medio. Aun así, no ha podido eliminarse la acción, ni destruir la frágil esfera de los asuntos humanos. Tratar estos últimos como productos planeados de fabricación humana por miedo a la inseguridad que provoca la acción ha tenido como resultado «canalizar la capacidad humana para la acción como si fueran meros procesos que sin los hombres no se hubieran iniciado».

Además, los seres humanos no son capaces de destruir o controlar los procesos que inician con la acción. Ni el olvido ni la confusión, que ocultan el origen y la responsabilidad de la misma, pueden deshacerla o impedir sus consecuencias ${ }^{13}$. Esta incapacidad de deshacer lo ya hecho se relaciona con la imposibilidad de predecir las consecuencias ${ }^{14}$ o conocer los motivos de una acción. El proceso de la acción se diferencia del de la producción en que el primero crece cuando se multiplican las consecuencias, mientras que el segundo queda absorbido en el producto final.

El porqué de la falta de predicción de la acción radica en que ésta no tiene fin. Quien actúa no puede hacerse kculpable» de las consecuencias indeseadas de su acción. Por eso mismo, el significado del acto nunca se revela al agente, sino a la mirada del espectador. El agente nunca puede conocer todas las consecuencias dc sus actos.

Frente a esta «desoladora contingencias, Arendt apunta modos para salir de las «encerronas" a las que parecen conducir las acciones. La frustración de la acciôn que nos muestra la irreversibilidad de la misma se salva mediante el perdón. Del mismo modo, el remedio de la impredecibilidad, de la inscguridad futura sc halla en la facultad de hacer y mantener promesas.

La facultad de perdonar y la de prometer dependen de la necesaria presencia de los otros. Fstas dimensiones pertenecen a la condición humana de la pluralidad. Perdonar implica deshacer los actos pasados ${ }^{15}$ y las promesas son la creación de un futuro sin inseguridades. Sin el perdón, siempre seriamos víctimas de las consecuencias de nuestras acciones y sin las promesas no podriamos mantener nuestras identidades, no apareceríamos en la esfera pública formada por los que prometen y los que cumplen, no nos insertariamos en esa trama construida a base de promesas y perdones. " $Y$ iquién puede decir de sí mismo: "De esta acción jamás podría yo haber sido culpable"? ${ }^{16}$.

Si habláramos de venganza en lugar de perdón, el individuo continuaría atado a las consecuencias de su acción. Sólo mediante el perdón son los seres humanos libres y pueden volver a empezar. Al mismo tiempo, el perdón no puede predecirse, manteniendo así algo de lo originario de la acción. El perdón es «una reacción que no reactúa», sino que vuelve a actuar, y de forma inesperada, libre de las consecuencias que lo originó.

La otra facultad, el hacer y mantener promesas, ejerce un dominio sobre la propia inseguridad que proviene de la libertad y sobre la imposibilidad de confiar en el 
futuro ${ }^{17}$. La promesa se convierte de este modo en la fuerza que mantiene unida a las personas (alo prometido es deuda»). El perdón y la promesa se convierten en los preceptos morales que no se aplican a la acción desde el exterior, sino que nacen del deseo de vivir juntos, son los mecanismos de control que inician nuevos e interminables procesos ${ }^{18}$. Para perdonar y para prometer, también se depende de los demás.

No cabe, pues, hablar de una responsabilidad única, individual, sino de una responsabilidad que, por referirse a la acción y a su carácter plural, nos aboca a entenderla como compartida. La acción se convierte, por todo ello, en la sfacultad humana de hacer milagros» y el mayor milagro, aquel que salva al mundo, es la natalidad. La historia y la vida son, desde este punto de vista, resultado de la acción. La historia es la gran narración sin comienzo ni fin y la vida es la historia que va desde el nacimiento hasta la muerte. Para Arendt la muerte es «resumir la vida en un acto único, de tal modo que la historia del acto termina con la vida misma», con esa vida cn la que nos vamos revelando gradualmente. Podemos decir que «los hombres aunque han de morit, no han nacido para eso sino para comenzar algo nuevos ${ }^{19}$. Y esto es así puesto que el tiempo de la acción es el tiempo de la pluralidad; el nosotros se convierte en condición de la acción: son los otros los que posibilitan nuestros comienzos.

\section{La identidad: el actor y el espectador}

El tránsito siguiente se produce en este momento en que la identidad aparece en un primer plano, es el momento en que las personas están con otras. Sólo así puede surgir el quién que dotará de significado a la acción. La remisión de la acción a la esfera pública nos muestra al agente. ¿Qué es ese estar con, ese estar «en medio de...»? Es la trama ${ }^{20}$ en la que nos insertamos, la red en la que el discurso toma su sentido de revelación del quién: el relato. Es con esa trama como es posible que la acción sea un nuevo comienzo de toda una serie de consecuencias que reinciden sobre el entramado inicial. Es dentro de cada trama, de cada historia, donde se hace la acción real y productiva, donde se producen historias con o sin intención de ello. En cada relato nace el sentido de la acción.

Sin embargo, aunque el hombre inicia su vida insertándose en esa trama que constituye el mundo humano por medio de la acción, no es él el autor de la historia de su propia vida (recordemos el anonimato). Las historias nos revelan a un agente, pero no a un autor. De este modo el actor pasa de ser agente a ser paciente, puesto que no cabe hablar de un único autor causante de una única acción si recordamos que las acciones son acabadas por otros.

Debido a las frustraciones de la acción, podemos sentirnos perplejos ante los acontecimientos que conforman una historia. Sólo puede aislarse al agente que puso todo el proceso en movimiento, al héroe, a aquel sobre el que puede contarse una historia puesto que tuvo el valor de comenzar algo nucvo. Otra vcz rccurro a Isak Dinesen: «una historia tiene un héroe, al que veis claramente luminoso y situado en un plano más alto. Sea cual fuese su condición, la historia inmortaliza al héroe» ${ }^{21}$. Sin embargo, este héroe, este agente, no es el autor del resultado final de la acción que inicia, «aunque las historias son los resultados inevitables de la acción, no es el actor, sino el narrador quien capta y hace la Historias, 22.

Estamos ante la dicotomía espectador-actor. El espectador es aquel que se retira del mundo, aquel que ya no actúa en él, es el sentido común, la intersubjetividad, aquel que observa el espectáculo; sin embargo, el actor es el que se halla inmerso en lo real, el que todavía perma- 
nece como «apariencia entre las apariencias». La realidad se presenta al espectador como «un puro y simple "estar ahi", siempre queda fuera de su alcance, inmutable ante su flujo» 23 . El sentido comín es el pensar cotidiano compartido por todos los seres humanos; es el que nos permite tener sensación de realidad $y$, al mismo tiempo (dada la pluralidad), permite la comunicación y la intersubjetividad. Para el actor, queda la apertura de posibilidades ${ }^{24}$. Y desde esas posibilidades vemos que la facultad que caracteriza a la acción es la Voluntad ${ }^{25}$, que «no se ocupa de objetos, sino de proyectos", es la fuente originaria de la acción, que «transforma el deseo en una intencion: 26.

Arendt aborda el tema de la Voluntad en La Vida del Espiritu, obra en la que se constatan abundantes resonancias kantianas. La autora murió dejando algunas páginas redactadas sobre el Juicio $\mathrm{y}$, aunque esta tercera parte de la obra se halla incompleta, pueden reconstruirse algunas de sus propuestas tomando como punto de partida algunas notas académicas y sus Lectures on Kants Political Philosophy ${ }^{27}$.

\section{El pensar: sus riesgos}

En la primera parte de este texto he intentado plasmar la interpretación arendtiana sobre la acción. La cuestión es ahora relacionar un cierto tipo de pensamiento con la caracterización de la acción que se ha hecho. Para Arendt existe un doble movimiento que se produce en la mente de cualquier persona, y por analogía en la historia intelectual de nuestro siglo, cesta persuna se revelaría como habiendo sido forzada a girar en redondo no una sino dos veces, primero cuando escapó del pensamiento hacia la acción y de nuevo cuando la acción, o mejor después de actuar, la forzó a retornar al pensamiento ${ }^{28}$. Volvamos al pensamiento.
La Vida del Espíritu se inicia afirmando que un cierto tipo de pensar ha muerto. Han muerto las «verdades eternas» $y$, junto a ellas, se ha enterrado también aquello que permitía distinguirlas (reconocerlas) como tales ${ }^{20}$. Ya Nietzsche había anunciado y denunciado que al abolir el mundo verdadero se derrumbaban también todas las apariencias ${ }^{30}$. Arendt señala los riesgos del pensar especulativo para, desde csa peligrosidad, proponer un pensamiento de la acción.

El primer riesgo del pensar es aquel constitutivo de la modemidad, que lo concebía bajo la forma del imperativo «se ha de buscar una verdad" ${ }^{31}$, de modo que el error es el precio que se ha de pagar por la verdad. Por lo tanto, si se quiere continuar hablando de ella, aunque sea entendiéndola como una «verdad fragmentada en un rosario de certezas", se sigue sin abandonar el ámbito que entiende la realidad como el afranzamiento de los fenómenos. Tal vez cabe pensar en una pluralidad de significados, la comprensión de los cuales viene posibilitada por el repensar una realidad abierta. Pero estos "significados» no pueden ser entendidos como meras apropiaciones de las «apariencias». Si se entendiesen de este modo, junto al precio del error, emergería la fantasmagórica ilusión y «... la ilusión es el precio que pagamos por las maravillas de las apariencias» ${ }^{32}$.

Si se concibe el saber del modo en que lo había enunciado Heráclito, es decir, «separado de todas las cosas» ${ }^{33}$, entonces, lo que hace el pensar es desensorizar el mundo. El pensar es una retirada del mundo de los fenómenos, retirada que hace la razón, lo especulativo. Pero la tarea del pensar no es la de producir verdades. La actividad del pensamiento ha de buscar el sentido de lo que ocurre, ha de buscar en lo invisible la comprensión de lo pasado.

Según Arendt, el pensar especulativo se distancia de lo real y, de cste modo, le acecha otro riesgo, caer en una reflexibi- 
lidad, en la conciencia de una actividad pura. Decía Kant: «la razón no se ocupa, de hecho, más que de sí misma. No puede tener otra ocupación» ${ }^{34}$. Contratiamente a esto, Arendt cree que el pensar no ha de ser algo solitario: la actividad del pensamiento ha de devenir pública, política.

Continuando el recorrido por los riesgos del pensar hemos de señalar aquel que implica la huida de la sorpresa: «las teorías que buscan la comprensión del mundo huyen de la sorpresa... que comporta admiración» ${ }^{35}$. El pensamiento se torna autodestructivo desde el momento en que el asombro no está nì en el inicio ni en el final. No encontramos asombro cuando se dogmatiza y se elude la duda, por lo tanto, es aconsejable dudar de lo pasado y de lo que está por venir.

Una de las salidas que hay para retornar el pensar a la realidad es la vinculación metafórica. Pero de este modo, tal vez, el pensar se enfrenta a un peligro todavia más destructivo. Si creemos que el pensar y la realidad se unen por la/s metáfora/s, entonces pensar podría convertirse en un producir metáforas. En último término al pensar le acecha el peligro de devenir techné.

Si seguimos cayendo en el dogmatismo, si creemos en una instancia única que nos permita reconocer nuestro entorno, hemos de tener en cuenta que: «El Yo-Pensante nunca será capaz de alcanzar la realidad como tal, ni de convencerse que algo existe en realidad y que la vida, la vida humana, es algo más que un sueños ${ }^{36}$.

Otro peligro que se cierne sobre al pensar es el nihilismo. Éste no siempre es resultado del pensar (que siempre es peligroso) pero puede aparecer cuando «aquello que tenía sentido mientras pensábamos desaparece cuando se aplica a lo cotidiano" ${ }^{37}$.

¿Qué nos queda como propuesta? No entender el pensar como aqucllo que abriendo la hendidura entre pasado y futuro (determinantes de su dirección), situándose en ella, pretende alcanzar el infinito.
El infinito o conceptos similares «no aparecen, no se ofrecen a nuestra experiencia», «no son para nosotros»" ${ }^{38}$. Desde esa brecha entre los dos tiempos, cabe «descubrir de nuevo y trazar afanosamente el camino del pensamiento* ${ }^{39}$, no tender a lo infinito, sino constatar las finitudes, recrearlas.

Tampoco podemos especular sobre un Yo-Pensante ominipresente que, por estar en todas partes, se encuentra en el «ninguna partes ${ }^{40}$, cabe pensar en un nosotros, siempre presente, siempre actual.

Sólo mediante la Voluntad y el Juicio retomamos al contacto con lo real, nos recuperamos de la escisión producida por el pensar y su separación de la realidad. He aquí la propuesta arendtiana: «¿Cuál es el objeto de nuestro pensar? iLa experiencia! iNada más! Y si perdemos el suelo de la experiencia entonces no encontramos con todo tipo de teorías» ${ }^{41}$.

\section{El repensar}

El pensar había sido visto como deseo de saber, como búsqueda de verdad, pero para Arendt el pensar es el deseo de comprender, la búsqueda de sentido ${ }^{42}$, de buscar sentido a la actualidad. El pensar no está separado de la realidad, vuelve a ella si lo concebimos como «repensamiento que se pinta después de la cosa» ${ }^{43}$, como reflexión. ¿Cómo podemos si no entender los cambios del presente?, ¿cómo seguir preguntándonos?, icómo continuar asombrados?

El pensar no es un instrumento para conocer. A Hannah Arendt le interesa la búsqueda del sentido, puesto que estamos en el ámbito de reflexión sobre lo humano, no en el campo de lo científico. El pensar ha de ser entendido como la labor de Penélope, como el reciclar lo pasado, como un repensar.

La salida a esa crisis del pensamiento especulativo que se había alejado de lo real 
pasa por ver el pensar como pensamiento politico, como pensamiento que indaga tras el ¿qué?, el ¿quién? y el ¿por qué?.. preguntas que nos permiten seguir pensando. El Yo-Pensante retorna al mundo cuando se pone en lugar del otro, cuando asume la alteridad ${ }^{44}$.

Ésta es la problemática central en la obra arendtiana: pensar la politica en plu$\mathrm{ral}^{45}$, pensar la política como espacio de comunicación entre sujetos que deliberan $y$ discuten sobre una diversidad irreductible. Por eso, la política es persuasión para Arendt, frente a la concepción de la política como violencia y coacción ${ }^{46}$, las cuales se muestran impotentes como cohesionadoras de lo plural, no unen porque no hablan: son mudas.

Arendt analiza la facultad del Juicio como la facultad política por excelencia. EI Juicio es la actividad en la que compartimos el mundo con los demás, puesto que en él, el espectador, quien juzga, no se encuentra solo, están los co-espectadores, la intersubjetividad. Es esta intersubjetividad la que permite que formemos parte del mundo y que no seamos meras apariencias ante los otros. Sólo por la intersubjetividad somos actores y espectadores al mismo tiempo. ¿Cómo nos ponemos en el lugar del otro? Por medio de la imaginación que se da en el Juicio, pasamos así a pensar con mentalidad extensa. Escribía Arendt en «Comprensión y política»: «Sin este tipo de imaginación, que en realidad es la comprensión, no seríamos capaces de orientarnos en el mundo. Es la única brújula intema de la que disponemos. Somos contemporáneos sólo husta dondc llega nuestra comprensión. Si queremos estar en armonía con esta tierra, incluso al precio de estar en armonía con este siglo, debemos participar en el interminable diálogo con su esencias ${ }^{4 ?}$.

Si el pensar especulativo imponia una retirada del mundo, el pensamiento politico posibilita ese retornar al mundo. Es desde la comunicación desde donde es posible el diálogo, la conversación con los otros. Hannah Arendt lo repite continuamente: xla discusión constituye la esencia de la políticas.

Lo político es entendido por Arendt como el ámbito que posibilita el espacio de aparición de las identidades al articular la pluralidad. La necesidad de rendir cuentas ante los demás muestra que sólo es posible el pensar en un espacio abierto al otro, en un espacio que cuente con los demás. El ejercicio de la capacidad de juzgar presupone la presencia de los otros y la posibilidad de su acuerdo: se trata ya de un espacio público. El sentido común, que mencioné unas líneas más arriba, es la custodia de ese espacio común. La apertura que hace el Juicio a la posibilidad de un espacio público tiene como condición la comunicabilidad. «El mundo, las cosas, sólo se vuelven humanas cuando las hablamos con nuestros semejantes» ${ }^{48}$.

El proyecto de Arendt es unificar moral y política en una ética de la responsabilidad por el mundo. «Humanizamos aquello que está sucediendo en el mundo y en nosotros mismo con el mero hecho de hablar sobre cllo y mientras lo hacemos aprendemos a ser humanos: 49 .

Puesto que el mundo se da entre los seres humanos, cuidar la pluralidad y la comunicación humana es el interés fundamental de la responsabilidad por el mundo. El Juicio se relaciona, desde esta caracterización, con el relato narrativo, con la reconciliación con el pasado, con la libertad como comienzo. Por eso escribc: «e! mundo está lleno de historias, de hechos y ocurrencias, de sucesos extraños que sólo aguardan a ser contados ${ }^{50}$, a ser comentados, comunicados y discutidos. El pensamiento político es pensamiento narrativo, puesto que su base radica en la intercomunicación, aunque no llega a buscarse un consenso universal. «Se hace necesario no cambiar el mundo, sino cambiar la manera de "evaluarlo", la manera de pensar y reflexionar sobre él» ${ }^{51}$. Podría aña- 
dirse: se hace necesario actuar sobre el mundo, reordenarlo, pero no como un detenerse, sino como un punto de partida, como un inicio, «revelar el significado de lo pasado en forma de historias ${ }^{52}$, pero esos inicios «que tienen lugar exclusivamente en el reino de los asuntos humanos, alli donde los hombres levantan un cuento para contarlo, para recordarlo, para preservarlo, son reestablecimientos y reconstituciones, y no comienzos absolutos" ${ }^{53}$.

Recordemos, por último, que como dijo Isak Dinesen, atodas las penas pueden soportarse si las ponemos en una historia o contamos una historia sobre ellas" ${ }^{54}$. Y que ese contar historias ya es pensamiento. «La propia razón, la capacidad para pensar de que disponemos, tiene necesidad de autorrealizarse. Los filósofos y los metafísicos la han monopolizado. Ello ha per- mitido grandes cosas, pero ha conllevado también algunas desagradables consecuencias: hemos olvidado que todo ser humano tiene necesidad de pensar, no de un pensamiento abstracto, ni de contestar a las consecuencias últimas acerca de Dios, la inmortalidad y la libertad, sino únicamente de pensar mientras vive. Cosa que hace constantemente. Cualquiera que cuente una historia de lo que le ocurrió hace media hora en la calle ha tenido que dar forma a este relato. Y el configurar el relato es una forma de pensamientom ${ }^{55}$. Pero hay que saber que se trata de un «pensar sin barandillas» ${ }^{56}$, un pensar que nos convierte en espectadores y que nos sitúa ante la experiencia. Se trata tan sólo de «pensar en lo que hacemos» ( $y$, tal vez, comprender lo que hacen los demás).
1 H. Arendt, The Human Condition, Univ. de Chicago Press, Chicago, 1958 (trad. cast.: La condición humana, Paidós, Barcelona, 1993, p. 210. En adelante emplearé $\mathrm{CH}$ para referirme a esta traducción).

$2 \mathrm{CH}, \mathrm{p} .18$.

${ }^{3}$ El metodo de trabajo arendtiano que ella defínió como arecorta y pegas posibilita que estas y otras nociunes aparezcan en distintos escritos, por ejeraplo, sobre las nociones mencionadas en el texto remito también a la conferencia eLabor, trabajo, acción», recogida en el volumen $\mathrm{H}$. Arendt, De la historia a la acción, Paidós, Barcelona, 1995.

4 CH, p. 202.

5 "Dado que a traves del nacimiento hemos entrado en el Ser, compartimos con las otras entidades la cualidad de la alteridad, un aspecto imporlante de la pluralidad que hace que sólo nos podamos definir por la distinción, esta es, no somos capaces de decir qué es algo sin distinguirlo de alguna otra cosa. [...] En el hombre, la alteridad y la distinción devienen unicidad, y lo que el hombre inserta con la palabra. y la acción en la sociedad de su propia especie es la unicidadm. H. Arendt, De la historia a la accion, op. cit, p. 103.
Ibid.

7 H. Arendt, The Life of the Mind, Harcourt Brace \& Co., Nueva York, 1978 (trad. cast.: La vida del Espiritu, la Woluntal y al Juicio en la Filosofia y en la Politica, Centro de Estudios Constitucionales, Madrid, 1984, p. 470 . En adelante citada como $L M$ ).

* H. Arendt, De la historia a la acción, op. cit., p. 104 .

"Yéase alsak Dinesen", an H. Arendt, Men in Dork Tines, Harcourt, Brace \& Worls, Nueva York, 1968 (trad. cast: Hombres en tiempos de oscuridad, Gedisa, Barcelona, 1900).

1. Dincsen, Ultimos cuentos, Bruguera, Barcelona, 1985, p. 31. Esta misma idea la ejemplifica Arendt en La Vida del Espiritu al narrar la historia de Ulises: *... cuando Ulises llega a la corte de Feacia y, por orden del rey, es entretenido por el aedo, que canta una historia extraída de la misma vida de Ulises, aquella de su disputa con Aquiles, al oírla, Ulises se cubre la cara y comienza a llorar, el que no habia llorado nunca, y ciertamente tampoco cuando aconteció lo que ahora está oyendo. Solo cuando escucha la historia lleza a ser plenamente consciente te su significadon, LM. p. 159 (cursiva C. C.). 
1 Dinesen, L, Camakal, Debate, Madrid, 1991, p. 249.

$12 \mathrm{CH}$, p. 228. Isak Dinesen nos dice en sus Cuenlos de invemo, Alfaguara, Madrid, 1986, p. 278: «un hombre no es más que lo que hace; tanto si construye barcos cono si hace relojes o armas o incluso libros. No puede llamarse bueno o excelente a un hombre. a menos que lo que haga sea grandex.

13 En la conterencia de 1957 sLabor, trabajo, accions lo expresa del siguicnte modo: waunque no sabemos lo que estamos haciendo, no tenemos ninguna posibilidad de deshacer lo que hemos hecho. Los procesos de la acción no son ś́lo impredecibles, son también irreversibles; no hay autor ofabricador que pueda deshacer, destruir, lo que ha hecho si no le gusta o cuando las consecuencias muestran ser desastrosasw, H. Arendt, De la historia de la accion, op-cit., p. 106.

1* Arendt insiste en que estas tres frustraciones diferencian a la acción del trabajo. Así en "Historia - Inmortalidad", un texto aparecido en 1957, aplica a la acción la expresión kamtiana de la «desoladora contingencia" y escribe: "La acción humana proyectada en una trama de relaciones donde muchos y opuestos fines son perscguidos, casi nunca realiza su intención original; ningún acto puede ser reconocido como propio por su autor con la misma feliz seguridad con que un producto de cualquier tipo de trabajo puede ser reconocido por su productor. Quienquiera que empieza a actuar sabe que ha empezado algo cuyo fin no puede nunca predecir, aunque sulo sea porque su propia acción ya ha cambiado todo y to ha convertido en más impredecible $* \mathrm{H}$. Arendt, De la historia a la acción, op. cit. p. 68 .

is Se perdonan personas, no acciones, puesto que no hay una responsabilidad encarnada en una única persona, sino que se trata de una responsabilidad compartida. Por eso Arendt, a pesar de la polémica, perdonó a Eichmann. Véase Eichmann en Jonusalén. Un estudio sobre la banalidad del mal, Lumen, Barcelona, 1967.

1. Dinesen, Cuentos de invieno, p. 235.

1" No puedo evitar incluir aquí las palabras que emplea Arendt para referirse a la importancia de las promesas. A pesar de que pueden sonar ingenuas para los tiempos que corren y acostumbrados cono estamos a que nos prometan cosas una y otra vez que bunca dejan de ser eso, meras promesas, creo que los términos que emplea pueden ayudanos a reflexionar sobre el tema. Dice en las páginas finales de «Labur, trabajo, acción": "Sin estar atados al cumplimiento de las promesas no seriamos nunca capaces de lograr el grado de identidad y continuidad que conjuntamente producen la "persona" acerca de la cual se puede contar una historia; cada uno de nosotros estaria condenado a errar desamparado, sin dirección, en la oscuridad de nuestro solitario corazón, atrapado en sus humores, contradicciones y equivocos. De la historia a la acción, op. cit., p. 107.

Is «Perdonar y hacer promesas son como mecanisntos de control establecidos en el propio seno de la facultad de inicias procesos nuevos y $\sin f i n{ }_{*}$ H. Arendt, De la historia a la acción, op. cit., p. 107.

${ }^{19} \mathrm{CH}$, p. 265 . Arendt cita repetidas veces la frase de Agustín "[Initium/ ergo ut esset, creatus est homo, ante quem nullus fuit, para que hubiera un comienzo. fuc creado el ser humano, antes del cual no había nadies.

30. Dondequicra que los hombres viven juntos existe una trama de relaciones humanas que está, por asi decirlo, urdida por los actos y las palabras de innumerables personas, tanto vivas como muertas. Toda nueva acción y todo nuevo comienzo cae en una trama ya existente, donde, sin embargo, empieza en cierto modo un nuevo proceso que afectará a muchos, incluso más alla de aquellos con los que el agente entra en un contacto directo.s De la historia a la acción, op. cit.. p. 105 .

21 1. Dinesen, Úlimos cuentos, p. 29.

in $C H, \mathrm{p}, 215$.

23 L. p. 69 .

24 «Pensaba cómo cambiando el tono de dos pala bras en una frase de todos los dias, cambiamos nuestro mundo. Porque mientras hablabas he pensado primero; " ¿Es posible?", y despues, al cabo de un momento: "Es posible".» I. Dinesen, Ulibmos cuentos, p. 63.

${ }^{25}$ Hannah Arendt hahla del kvientre de la memoriaw: se recuerda con la memoria que pone a disposición del recuetdo lo que ya no es, pero se anticipa con la voluntad que aporta lo que vendră en el futuro, lo que aún no es.

*M, p. 95 .

"H. Arendt, Lectures on Kants Political Philosophy, ed, de R. Beiner, The University of Chicago Press, Chicago, 1982.

${ }^{2 x} \mathrm{H}$. Arendt, "La brecha entre el pasado y el futuro", prefacio a Between Past and Future, Viking Press, Nucva York, 1961 (trad. cast.: Entre el pasado y el futuro, Peninsula, Barcelona, 1996, p. 15). Opto por la traducción de este prefacio que se incluye en De la historia a la acción, op. cit., p. 82.

29 Escribe Arendt: «Los muertos son "sepultados" en el recuerdo como preciosas reliquias de ellos mismos", LM, p. 457.

"Escribia Nictzsche en "Cómo el "Mundo Verdadero" acabó convirtiéndose en una fábula»: «Hemos abolido el mundo verdadero: ¿qué hà quedado? ¿Quizá 
aquel de la apariencia?... Pero, inot Con el mundo verdadero hemos abolido también el mundo de las apariencias». F. Nietzsche, Creprisculo de los ídolos, Alianza, Madrid, 1986, p. 52. H. Arendt cita este texto en $L M$, p. 21. W. H. Auden, gran amigo de Arend, Io poetizaha a su modo en wistoria de la Verdad:

En tiempos pasados, cuando ser era creer,

la verdad era la mayoría de menas cosas ereibles

más primera. y más elerna, que los leones alados,

los perros medio pez o los peces con cabeza de äguila, lo mínimo como los nortales, de quien la muerte hace dudar. La verdadera el modelo mitentras se esforzaban por construit un mundo de obivtos duraderos en qué creer sin pensar si lozas de barro y leyendas. arcadas y canciones, eran vetaderas o falsas; la Verdad ya estaba aquí, para no mentir. Abora que, práctica como platos de papel, la Verdad es convertible en kilovatios, la ultima cosa que hemos de hacer es un antimodelo, alguna faisedad que todo el mundo pueda desmentir una nada que nadic no tenga que creer que cetá aquí.

s. $L M$, p. 53 .

s2 LM, p. 53.

3 Fragmento 108.

at Kr/B 708 .

"LM, p. 164 .

36. LM, p. 228.

"LM, p. 208.

\$ LM, p. 56 .

$2 M$, p. 240.

L LM, p. 239.

" La cita procede de una intervención de Hannah Arendt en un congreso sobre su obra, algunas de las transcripciones aparcen traducidas on «Arendt sobre Arendt”, De la historia a la acción, op. cit., p. 145.

$\$ 2$ Dice Arendt en una entrevista publicada en Saber, núm. 13, primavera de 1987, p. 21: "Lo que es esencial para mí es comprender: he de comprender» (cursiva C. C.).
43 $L M$, p. 28 .

4. sLa unidad de la humanidad $y$ su solidaridad no pueden consistir en un acueralo universal sobre una religión, o una sola filosofía o una forma de gobierno, sino en la creencia de que los varios aspectos que forman una unidad se manifiestan y ocultan al mismo tiempo en la diversidadx, H. Arendt, Hombres en tiempos de oscuridad, p. 75 .

45 "La autếntica acción política aparece como un acto de un grupo. $Y$ uno se une o no al grupo. $Y$ cualquier cosa que se haga por cuenta propia indica que mo se es un agente: se es un anarquista.»H. Arendt, De la historia a la acción, op. cit., p. 146.

t Formas politicas que surgen bajo el espectro del totalitarismo, Remito al análisis que hace Arendt en Los origenes del Totalitarismo (3 vols.), Alianza, Madrid, 1987.

47. Arendt, De la historia a la acción, op. cit., p. 46.

4. Toscano Méndez «Juicio y comunicación en Hannah Arendt: una lectura política de La Critica del Jicion, Sistema, num. 99, novicmbre 1990, p. 127.

${ }^{4}$ H. Arendt, Hombres en tiempos de oscuridad, p. 35 .

5n H. Arendt, Hombres en tiempos de oscuridad, p. 83.

5) $L M$, p. 443.

s CH, p. 215 (cursiva C. C).

s. $L, \mathrm{p}, 492$.

1. Dinesen, citada por H. Arendt en CH, p. 199.

35 H. Arendt, De la historia a la acción, op. cit. p. 139.

56 Arendt afirma que la manifestación del pensar «es la capacilad de distinguir lo bueno de lo malo, lo bello de lo fco. Y cllo, en los raros momentos en que se ha llegado a un punto eritico, puede prevenir catástrofes, al menos para mín. De la historia a la acción, op. citr, p. 137. 